\title{
Long-Term, Real-World Safety and Efficacy of Teneligliptin: A Post-Marketing Surveillance of More Than 10,000 Patients with Type 2 Diabetes in Japan
}

\author{
Takashi Kadowaki - Masakazu Haneda - Hiroshi Ito · Kazuyo Sasaki (D) • \\ Miyuki Matsukawa · Yuka Yamada
}

Received: October 25, 2019 / Published online: December 23, 2019

(C) The Author(s) 2019

\section{ABSTRACT}

Introduction: Teneligliptin is a dipeptidyl peptidase 4 inhibitor that was approved for the treatment of type 2 diabetes mellitus (T2DM) in Japan in 2012. We performed a long-term postmarketing surveillance (RUBY) to obtain realworld evidence regarding the safety and efficacy of teneligliptin in Japan.

Methods: This 3-year follow-up RUBY surveillance registered patients with T2DM who started treatment with teneligliptin between May 2013 and February 2015 in Japan. Collected data included demographics, treatments,

Enhanced Digital Features To view enhanced digital features for this article go to https://doi.org/10.6084/ m9.figshare.11298191.

Electronic supplementary material The online version of this article (https://doi.org/10.1007/s12325019-01189-w) contains supplementary material, which is available to authorized users.

T. Kadowaki

Department of Diabetes and Metabolic Diseases, Graduate School of Medicine, The University of

Tokyo, Tokyo, Japan

T. Kadowaki

Department of Metabolism and Nutrition, Faculty of Medicine, Mizonokuchi Hospital, Teikyo University, Tokyo, Japan

M. Haneda

Department of Medicine, Asahikawa Medical

University, Hokkaido, Japan adverse drug reactions (ADRs) and laboratory variables. Data were evaluated in all patients and in patients divided according to baseline renal function across categories of estimated glomerular filtration rate (G1-G5) and dialysis. Safety was assessed as the incidence of ADRs and efficacy was assessed in terms of glycaemic control, for up to 3 years.

Results: Of 11,677 patients registered, 10,696 and 10,249 were evaluable for safety and efficacy analyses, respectively. The median duration of exposure was 1096 days. ADRs occurred in 412 patients (3.85\%) and were serious in 117 patients (1.09\%). The most frequent ADR class was gastrointestinal disorders $(0.68 \%)$, which included constipation. There were no new ADRs warranting attention beyond those already described in teneligliptin's package insert. ADRs and serious ADRs in renal function subgroups occurred in $3.24-7.14 \%$ and $0.65-5.36 \%$ in G1-G5, and $4.49 \%$ and $1.92 \%$ in patients on

M. Haneda

Medical Corporation Kyousoukai, Osaka, Japan

H. Ito

Department of Cardiovascular Medicine, Okayama

University, Okayama, Japan

K. Sasaki $(\bowtie) \cdot$ M. Matsukawa · Y. Yamada Ikuyaku, Integrated Value Development Division, Mitsubishi Tanabe Pharma Corporation, Osaka, Japan

e-mail: Sasaki.Kazuyo@mh.mt-pharma.co.jp 
dialysis, respectively. Reduction in HbA1c was sustained for 3 years after starting teneligliptin $(-0.70 \% \pm 1.36 \%, p<0.001$ at 3 years $)$. The least-squares mean changes in HbA1c adjusted for baseline were $-0.76 \%$ to $-0.66 \%$ in G1-G5 at 3 years. Glycated albumin levels decreased in patients on dialysis $(-2.92 \% \pm 4.78 \%$ at 3 years).

Conclusion: There were no new safety or efficacy concerns about teneligliptin used in longterm, real-world, clinical settings in patients with T2DM with any stages of renal impairment.

Trial registration: Japan Pharmaceutical Information Center clinical trials database identifier: Japic CTI-153047.

Plain Language Summary: Plain language summary available for this article.

Keywords: Dipeptidyl peptidase 4 inhibitor; Post-marketing surveillance; Real-world; Renal impairment; Teneligliptin; Type 2 diabetes mellitus

\section{Key Summary Points}

Why carry out this study?

Teneligliptin is a dipeptidyl peptidase 4 inhibitor that was approved for the treatment of type 2 diabetes mellitus (T2DM) in Japan in 2012.

Clinical trials are often limited in terms of their duration, number of patients, and the background characteristics of patients, including renal impairment.

We performed a post-marketing surveillance of teneligliptin to examine the long-term (3 years) safety and efficacy in real-world clinical practice, including in patients with renal impairment and those on dialysis.

What was learned from the study?

Long-term treatment with teneligliptin for up to 3 years had a safety profile consistent with that observed in clinical trials.

\section{PLAIN LANGUAGE SUMMARY}

Teneligliptin is a once-daily oral dipeptidyl peptidase 4 inhibitor for treatment of type 2 diabetes. Although many clinical trials assessed the safety and efficacy of teneligliptin, these were limited in terms of number of patients, patient background characteristics, and study duration. Therefore, to investigate the longterm safety and efficacy of teneligliptin in patients with type 2 diabetes in real-world settings, we conducted a 3 -year follow-up postmarketing surveillance of teneligliptin in more than 10,000 patients with type 2 diabetes in Japan. Patients were also divided into subgroups according to their estimated glomerular filtration rate (grade 1 , least severe to grade 5 , most severe) and patients on dialysis. Adverse drug reactions occurred in $3.85 \%$ of 10,696 patients. The most frequent type of adverse drug reaction was gastrointestinal disorders $(0.68 \%)$, which included constipation. There were no new adverse drug reactions that warrant attention beyond those already described in teneligliptin's information leaflet or package insert. Among patients divided by grade of renal impairment, adverse drug reactions occurred in $3.24-7.14 \%$ in grade $1-5$ and in $4.49 \%$ of patients on dialysis. We also found that teneligliptin lowered haemoglobin A1c, a marker of glycaemic control, by $0.70 \%$ at 3 years in the overall study group, with similar decreases in patients in each grade of renal impairment. A decrease in glycated albumin was observed in patients on dialysis. These findings demonstrate that there were no new safety or efficacy concerns about teneligliptin used in long-term, real-world, clinical settings in patients with type 2 diabetes, including those with chronic kidney disease or on dialysis.

\section{INTRODUCTION}

The burden of type 2 diabetes mellitus (T2DM) is rapidly growing worldwide [1] and in Japan [2]. According to a 2016 report by the National Health and Nutrition Survey in Japan, there were an estimated 10 million adults in whom diabetes is strongly suspected and a further 
10 million in whom the possibility of diabetes cannot be ruled out [2]. T2DM is also associated with high rates of comorbidities and diabetic complications, especially diabetic nephropathy. Diabetic nephropathy is the most common cause of renal failure in patients starting dialysis [3]. In order to reduce the risk of diabetic complications, guidelines for the management of diabetes have set goals for glycaemic control [4-6]. Impaired renal function can also affect drug elimination, which may necessitate dose reductions of renally eliminated drugs, and some drugs, notably metformin, are contraindicated in patients with renal impairment [7]. In addition, renal impairment causes reductions in insulin clearance and impaired renal gluconeogenesis, which impact on risk of developing hypoglycaemia [8].

Dipeptidyl peptidase 4 (DPP4) inhibitors are among the widely used classes of drugs available for the treatment of T2DM; in Japan, DPP4 inhibitors are used as first-line therapy in about $60 \%$ of patients [9]. The high use of DPP4 inhibitors in Japan may be explained by differences in the pathophysiology of T2DM in Asian patients, including reduced $\beta$-cell function and less-prominent insulin resistance, as well as differences in dietary factors and genetic disposition, as compared with other populations $[10,11]$. All of these factors may contribute to the greater efficacy of DPP4 inhibitors in Asian populations including Japanese patients [12].

Teneligliptin, a DPP4 inhibitor, was approved in Japan in 2012 and subsequently in Korea in 2014 [13]. The clinical trials for teneligliptin demonstrated its efficacy and safety as monotherapy $[14,15]$ or in combination with oral antidiabetic agents or insulin [16-22]. In Japan, teneligliptin is administered at a dose of $20 \mathrm{mg}$ once daily. On the basis of the approved label [23], if the prescribing physician thinks the patient's glycaemic control is inadequate, the dose of teneligliptin can be increased to $40 \mathrm{mg}$ once daily with close monitoring of the patient. Teneligliptin can be used without the need for dose adjustment in patients with T2DM and impaired renal function, including those on dialysis, because of its unique pharmacokinetic profile involving elimination by multiple pathways: hepatic metabolism by cytochrome P450 3A4 and flavin-containing monooxygenase 3 or excretion in an unchanged form by the kidney [13].

Clinical trials are often limited in terms of their duration, number of patients and the background characteristics of patients, including renal impairment. Therefore, drug surveillance can provide additional information on the safety and efficacy of newly approved drugs by accumulating data from a larger number of patients treated in real-world settings.

From this context, a post-marketing surveillance (RUBY; ExploRing the long-term efficacy and safety including cardiovascUlar events in patients with type 2 diaBetes treated bY teneligliptin in the real-world) was implemented in Japan with the key objectives of examining the long-term (3 years) safety and efficacy of teneligliptin in more than 10,000 patients with T2DM in real-world settings [24-26]. In this report, we describe the 3-year safety and efficacy of teneligliptin in RUBY. We also examined the safety and efficacy in patients with each renal impairment stage and in patients on dialysis.

\section{METHODS}

\section{Ethics}

The surveillance protocol was approved by the Ministry of Health, Labour and Welfare of Japan, and was performed by Mitsubishi Tanabe Pharma Corporation in accordance with the Japanese ministry directive on Good Post-marketing Study Practice (GPSP). The surveillance used anonymous data collected in clinical practice in Japan. In accordance with Japanese regulations for post-marketing surveillance, it is not necessary to obtain informed consent from patients. RUBY was registered on the Japan Pharmaceutical Information Center clinical trials database (Japic CTI-153047).

\section{Patients and Surveillance Design}

Patients with T2DM who were first prescribed teneligliptin between May 2013 and February 2015 were to be registered by their prescribing physician in RUBY. Patients were to be followed 
up for a maximum of 3 years through to August 2018. All data were to be recorded using electronic case report forms and the database was locked in January 2019. All treatment decisions, including the teneligliptin therapy, the combination antidiabetic therapies and treatments for comorbidities, were at the prescribing physician's discretion in accordance with the approved label or regimen. Teneligliptin dose could be increased to $40 \mathrm{mg}$ once daily if $20 \mathrm{mg}$ was deemed insufficient by the prescribing physician.

The prescribing physicians used electronic case report forms to record information on baseline demographic information, comorbidities, renal function, treatment status, clinical laboratory tests, and adverse drug reactions (ADRs), adverse events (AEs) and compiled data until 3 years after registration. Laboratory test data included HbA1c, fasting blood glucose (FBG) and lipids, which were to be recorded at 0 , $3,6,12,18,24,30$ and 36 months after starting teneligliptin. The laboratory analyses were conducted using routine clinical assays in the institution participating in the surveillance. Estimated glomerular filtration rate (eGFR) was calculated from age, gender and serum creatinine levels recorded in the case report forms using the Japanese eGFR equation [27]. Glycated albumin was recorded in patients on dialysis.

Safety was assessed in terms of the incidence of ADRs, and efficacy was assessed in terms of glycaemic control, up to 3 years. All ADRs were classified using the Medical Dictionary for Regulatory Activities (MedDRA)/Japanese version 21.1. ADRs were defined as AEs for which a causal relationship with teneligliptin could not be excluded, i.e. related or unknown, by either the prescribing physician or Mitsubishi Tanabe Pharma Corporation, or both of them. The seriousness of ADRs and AEs was judged according to the following definitions: death, life threatening, requirement inpatient hospitalisation or prolongation of existing hospitalisation, persistent or significant disability/ incapacity, congenital anomaly or birth defect, or a medically important event or reaction. For this surveillance, serious hypoglycaemia was defined as blood glucose level of $\leq 50 \mathrm{mg} / \mathrm{dL}$ or diagnosis by the prescribing physician. ADRs of special interest included ADR related to hypoglycaemia, skin and subcutaneous tissue disorders (including pemphigoid), gastrointestinal disorders (including pancreatitis and intestinal obstruction), hepatic impairment, renal impairment, cardiovascular events and malignant tumours. In addition, the frequencies of AEs related to cardiovascular events and malignant tumours were assessed. These special interest ADRs and AEs were defined using preferred terms (PT) and system organ class (SOC) of MedDRA or standardised MedDRA queries (SMQ). Cardiovascular events were defined using two broad SMQ: "myocardial infarction" and "central nervous system haemorrhage and cerebrovascular conditions".

Safety and efficacy analyses were performed for the overall population and for patients divided into renal impairment stage at baseline. For the stratified analysis of renal impairment stage, patients were divided into those receiving and those not receiving dialysis at the initiation of teneligliptin. Non-dialysis patients with eGFR at baseline were classified according to their renal function using the following eGFR categories for CKD [28]: G1, eGFR $\geq 90 \mathrm{~mL} / \mathrm{min} /$ $1.73 \mathrm{~m}^{2}$; G2, eGFR 60 to $<90 \mathrm{~mL} / \mathrm{min} / 1.73 \mathrm{~m}^{2}$; G3a, eGFR 45 to $<60 \mathrm{~mL} / \mathrm{min} / 1.73 \mathrm{~m}^{2}$; G3b, eGFR 30 to $<45 \mathrm{~mL} / \mathrm{min} / 1.73 \mathrm{~m}^{2}$; G4, eGFR 15 to $\quad<30 \mathrm{~mL} / \mathrm{min} / 1.73 \mathrm{~m}^{2}$; and G5, eGFR $<15 \mathrm{~mL} / \mathrm{min} / 1.73 \mathrm{~m}^{2}$. If patients started dialysis during the observation period, data recorded prior to dialysis were used to assess HbA1c and eGFR in the eGFR category.

We also examined the safety and efficacy of increasing the teneligliptin dose to $40 \mathrm{mg}$. Efficacy analyses were performed for patients who received the increased dose of $40 \mathrm{mg}$ once daily for $\geq 8$ weeks if their $\mathrm{HbA1c}$ was measured before and after increasing the dose during the observation period.

The design of this surveillance was described in more detail in the prior interim analysis reports $[24,25]$.

\section{Statistical Analyses}

All statistical analyses were performed using SAS statistical software version 9.1 .3 or later. Data were analysed using safety and efficacy analysis 
sets, as appropriate. The safety analysis set comprised all registered patients who underwent safety assessments, while the efficacy analysis set comprised all patients in whom efficacy outcomes were evaluated. The analysis did not take into account any changes in concomitant antidiabetic drugs or lifestyle modifications during the observation period. Categorical variables are presented as frequencies and percentage and continuous variables are presented as descriptive statistics. For ADRs or AEs of special interest, the risk ratio of its incidence and the 95\% confidence interval (CI) were calculated for each eGFR category, and the uniformity of the incidence rate was evaluated. Paired $t$ tests were used to test for changes in continuous variables from baseline, except for eGFR, which was assessed using the Wilcoxon signed rank test. All tests were conducted at a two-sided significance level of 5\%. The least squares (LS) mean and standard error (SE) for the change from baseline in HbA1c at each time point were determined and the significance test was performed for difference between eGFR categories by analysis of covariance (ANCOVA) with HbA1c at baseline as a covariate. Missing data were not handled at each time point, but missing data were replaced with substituted values using the last observation carried forward method for the final time point.

\section{RESULTS}

\section{Patients}

Overall, 11,677 patients were initially registered in RUBY across 1755 centres, and survey forms were collected for 11,355 patients. Of these, 10,696 and 10,249 patients were included in the safety and efficacy analyses, respectively (Fig. 1). A total of 3680 patients (34.4\%) discontinued treatment or dropped out before 3 years of treatment for the following reasons (multiple reasons were possible): visit stopped ( $n=1208$, $32.8 \%)$, transfer to another hospital $(n=915$, $24.9 \%)$, the physician believed the therapeutic effect to be insufficient ( $n=604,16.4 \%), \mathrm{AE} /$ ADR ( $n=308,8.4 \%)$, the patient's symptoms of T2DM improved or recovered sufficiently to allow treatment to stop $(n=270,7.3 \%)$ or another reason $(n=481,13.1 \%)$.

The median duration of exposure in the safety analyses set was 1096 days (25-75th percentile 500-1096 days). The teneligliptin dose was increased at the prescribing physician's discretion from 20 to $40 \mathrm{mg}$ in 220 (2.1\%) patients at a median of 183.5 days after starting treatment. The median duration of the increased dose was 597 days.

The baseline characteristics of patients in the safety analyses set are summarised in Table 1 . The mean \pm standard deviation (SD) age, duration of T2DM and body mass index were $65.4 \pm 12.4$ years, $\quad 7.41 \pm 7.87$ years and $25.24 \pm 4.40 \mathrm{~kg} / \mathrm{m}^{2}$, respectively. The mean \pm SD HbA1c and FBG at the start of teneligliptin were $7.75 \pm 1.53 \%$ and $151.7 \pm 52.4 \mathrm{mg} / \mathrm{dL}$, respectively. The proportions of patients on dietary therapy and exercise therapy were $76.1 \%$ and $58.8 \%$ at baseline, respectively. Diabetic complications and other comorbidities (hypertension and dyslipidaemia) were present in about one-quarter and two-thirds of patients, respectively.

Teneligliptin was prescribed as monotherapy in $5126(47.9 \%)$ of patients and as combination therapy with sulfonylureas (2685 patients, $25.1 \%$ ) and/or biguanide (2294 patients, $21.4 \%$ ) being the most commonly used combination therapies during the observation period (Supplemental Table 1). Most of the patients who were also taking a sulfonylurea complied with the recommended doses of glimepiride $(\leq 2.0 \mathrm{mg})$, gliclazide $(\leq 40 \mathrm{mg})$ and glibenclamide $(\leq 1.25 \mathrm{mg}$ ) [29], with compliance rates of $84.7 \%$ for glimepiride (1680/1984 patients), $81.8 \%$ for gliclazide (184/225 patients) and $25.0 \%$ for glibenclamide (35/140 patients). As indicated in Supplemental Table 1, there were no marked changes in the rates of concomitantly used agents between the start and 3 years of teneligliptin, except for an increase in concomitant use of sodium-glucose cotransporter 2 inhibitors, which were launched during this period. Overall, 5372 (50.2\%) and 4436 (41.5\%) patients received antihypertensive and antidyslipidaemic agents during the observation period, respectively. 


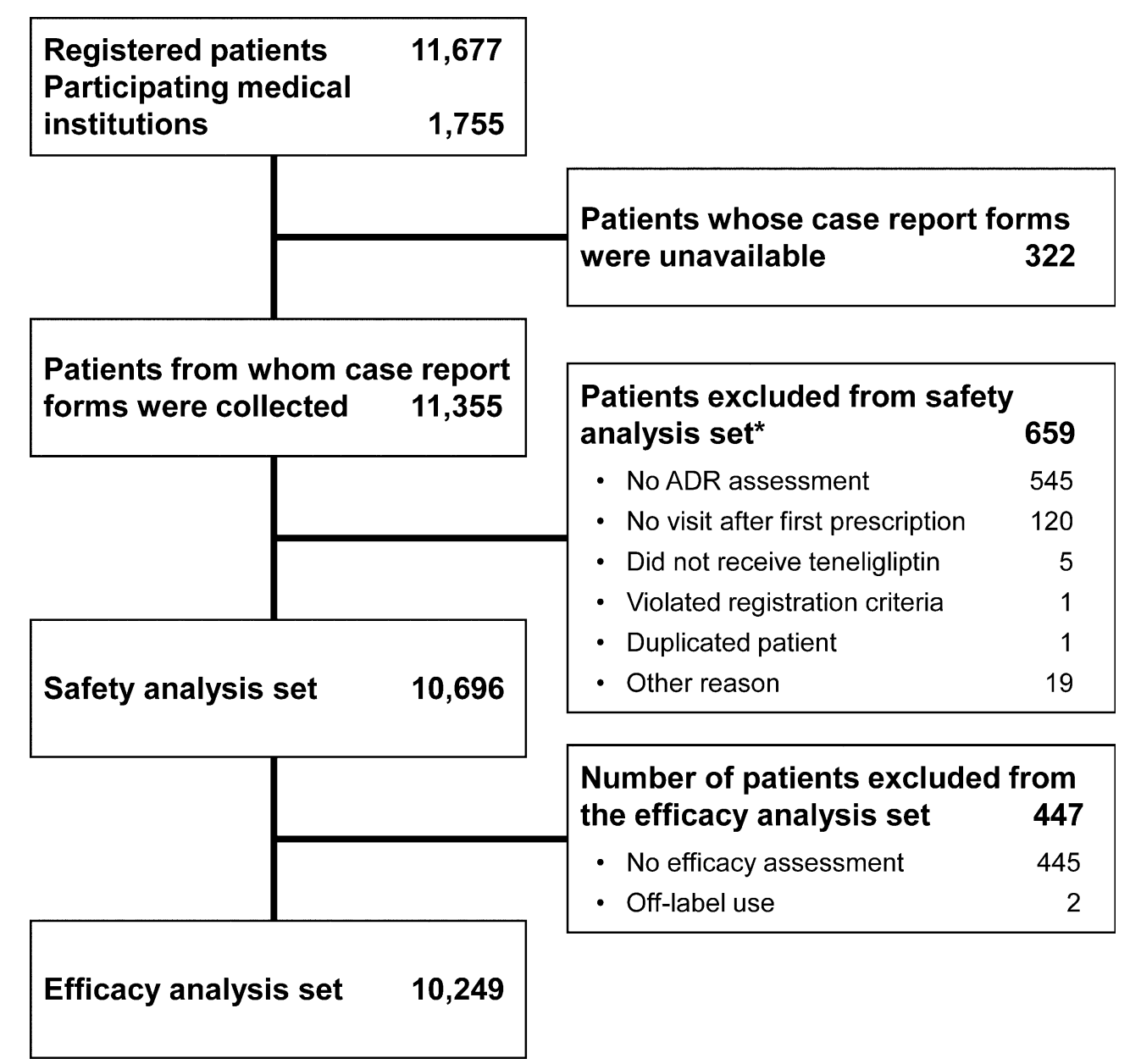

Fig. 1 Patient disposition. $A D R$ adverse drug reaction. ${ }^{*}$ Multiple reasons may apply for some patients

Of the 10,696 patients in safety analysis set, eGFR was calculable at baseline for 9382 nondialysis patients. Renal function was classified as G1 in 2008 patients, G2 in 5015 patients, G3a in 1525 patients, G3b in 561 patients, G4 in 217 patients and G5 in 56 patients. A further 156 patients were on dialysis at baseline. The characteristics of these seven subgroups are summarised in Supplemental Table 2. Notable findings are that the duration of T2DM and the rate of diabetic and non-diabetic comorbidities tended to increase with increasing CKD grade. The teneligliptin dose was increased to $40 \mathrm{mg}$ in 41 patients with eGFR $<45 \mathrm{~mL} / \mathrm{min} / 1.73 \mathrm{~m}^{2}$ or on dialysis at a median of 475 days in G3b, 907 days in G4, 338 days in G5 and 149 days in patients on dialysis. Dialysis was started during the observation period in 15 patients. Supplemental Table 3 also shows the concomitant use of agents for
T2DM, hypertension and dyslipidaemia, and of erythropoiesis-stimulating agents.

\section{Safety}

\section{Overall Population}

A total of 489 ADRs occurred in 412 of 10,696 patients (3.85\%) with 133 serious ADRs in 117 patients (1.09\%). ADRs of special interest and AEs of cardiovascular events and malignant tumours in the overall population are listed in Table 2 and Supplemental Table 4. Supplemental Table 5 provides a list of ADRs by system organ class and preferred term. The most frequent ADR of special interest was gastrointestinal disorders $(0.68 \%)$, including constipation $(0.27 \%)$, intestinal obstruction (ileus) $(0.04 \%)$ and pancreatitis $(0.01 \%)$. Hypoglycaemia- 
Table 1 Patient characteristics (safety analysis set, $n=10,696$ )

\begin{tabular}{|c|c|}
\hline Characteristic & Value \\
\hline \multirow[t]{2}{*}{ Sex, male/female } & $6439(60.2 \%) /$ \\
\hline & $4257(39.8 \%)$ \\
\hline Age, years & $\begin{aligned} 65.4 & \pm 12.4 \\
(n & =10,696)\end{aligned}$ \\
\hline Duration of $\mathrm{T} 2 \mathrm{DM}$, years & $\begin{array}{r}7.41 \pm 7.87 \\
\quad(n=7338)\end{array}$ \\
\hline BMI, $\mathrm{kg} / \mathrm{m}^{2}$ & $\begin{array}{r}25.24 \pm 4.40 \\
(n=7123)\end{array}$ \\
\hline$<18.5$ & $239(2.2 \%)$ \\
\hline$\geq 18.5$ to $<22$ & $1319(12.3 \%)$ \\
\hline$\geq 22$ to $<25$ & $2212(20.7 \%)$ \\
\hline$\geq 25$ to $<30$ & $2458(23.0 \%)$ \\
\hline$\geq 30$ & $895(8.4 \%)$ \\
\hline Unknown & $3573(33.4 \%)$ \\
\hline HbAlc, \% & $\begin{array}{r}7.75 \pm 1.53 \\
(n=9821)\end{array}$ \\
\hline $\mathrm{FBG}, \mathrm{mg} / \mathrm{dL}$ & $\begin{array}{r}151.7 \pm 52.4 \\
(n=3719)\end{array}$ \\
\hline eGFR, $\mathrm{mL} / \mathrm{min} / 1.73 \mathrm{~m}^{2}$ & $\begin{array}{c}74.01 \pm 23.27 \\
(n=9382)\end{array}$ \\
\hline Diet therapy & $8139(76.1 \%)$ \\
\hline Exercise therapy & $6290(58.8 \%)$ \\
\hline \multicolumn{2}{|l|}{ Diabetic complications } \\
\hline Any & $2796(26.1 \%)$ \\
\hline Retinopathy & $1075(10.1 \%)$ \\
\hline Neuropathy & $1063(9.9 \%)$ \\
\hline Nephropathy & $2000(18.7 \%)$ \\
\hline \multicolumn{2}{|l|}{ Other complications } \\
\hline Hypertension & $6705(62.7 \%)$ \\
\hline Dyslipidaemia & $7025(65.7 \%)$ \\
\hline Heart disease & $1849(17.3 \%)$ \\
\hline $\begin{array}{l}\text { Ischaemic heart disease (MI, } \\
\text { angina pectoris) }\end{array}$ & $1035(9.7 \%)$ \\
\hline
\end{tabular}

Table 1 continued

\begin{tabular}{ll}
\hline Characteristic & Value \\
\hline Heart failure & $446(4.2 \%)$ \\
\hline
\end{tabular}

Values are number (\%) of patients or mean \pm standard deviation (number of patients)

T2DM type 2 diabetes mellitus, $H b A 1 c$ haemoglobin A1c, $F B G$ fasting blood glucose, $B M I$ body mass index, $e G F R$ estimated glomerular filtration rate, $M I$ myocardial infarction

related ADRs occurred in 38 patients $(0.36 \%)$, and were classified as serious in 8 patients $(0.07 \%)$; all 8 patients were using sulfonylurea or insulin. There were no episodes of serious hypoglycaemia among patients using teneligliptin alone although non-serious hypoglycaemia was reported in nine of those patients. Skin and subcutaneous tissue disorders occurred in 44 patients $(0.41 \%)$. Pemphigoid was reported in five patients $(0.05 \%)$ and all cases were classified as serious. Except for one patient with an unknown outcome, pemphigoid resolved or improved after discontinuation of teneligliptin or administration of corticosteroids. Of these five patients with pemphigoid, four were $\geq 75$ years old and the time to onset of these events was $\geq 11$ months after starting teneligliptin. Hepatic impairment and renal impairment occurred in $0.44 \%$ and $0.32 \%$ of patients, respectively. Cardiovascular events were reported as AEs in 85 patients $(0.79 \%)$ and as ADRs in 18 patients $(0.17 \%)$, which included 14 patients $(0.13 \%)$ with serious ADRs. Malignant tumours were reported as AEs in 111 patients (1.04\%) and as ADRs in 27 patients $(0.25 \%)$. All malignant tumours reported as ADRs were classified as serious. The most common malignant tumour type was pancreatic carcinoma, which was reported as an AE in 15 patients $(0.14 \%$; 0.06 per 100 patient-years) and as an ADR in 5 patients $(0.05 \%$; 0.02 per 100 patient-years). ADRs other than those of special interest that occurred in $\geq 0.1 \%$ of patients included dizziness, which occurred in 11 patients $(0.10 \%)$, but none of the episodes were considered serious. Death was reported for six patients, although the causal relationship with teneligliptin was unknown in four patients or 
Table 2 ADRs and AEs of special interest

\begin{tabular}{lcl}
\hline Patients analysed for safety & $\mathbf{1 0 , 6 9 6}$ & \\
\cline { 2 - 3 } & All ADRs & $\begin{array}{l}\text { Serious } \\
\text { ADRs }\end{array}$ \\
\hline $\begin{array}{l}\text { Number of patients with } \\
\text { ADRs }\end{array}$ & 412 & $117(1.09 \%)$ \\
& $(3.85 \%)$ &
\end{tabular}

Number of events of ADRs 489 events 133 events

Hypoglycaemia-related ADRs

$$
\begin{array}{lll}
N(\%) & 38(0.36 \%) & 8(0.07 \%) \\
\text { Per 100 patient-years } & 0.15 & 0.03
\end{array}
$$

Skin and subcutaneous tissue disorders, ADRs

$$
\begin{array}{lll}
N(\%) & 44(0.41 \%) & 6(0.06 \%) \\
\text { Per 100 patient-years } & 0.17 & 0.02
\end{array}
$$

Gastrointestinal disorders, ADRs

$$
\begin{array}{lll}
N(\%) & 73(0.68 \%) & 12(0.11 \%) \\
\text { Per 100 patient-years } & 0.29 & 0.05
\end{array}
$$

Hepatic impairments, ADRs

$$
N(\%)
$$

Per 100 patient-years

$$
47(0.44 \%) \quad 4(0.04 \%)
$$$$
0.18 \quad 0.02
$$

Renal impairments, ADRs

$$
N(\%)
$$

Per 100 patient-years

$$
34(0.32 \%) \quad 7(0.07 \%)
$$

$$
0.13 \quad 0.03
$$

Cardiovascular events, $\mathrm{AE}$

$$
\begin{array}{lll}
N(\%) & 85(0.79 \%) & 76(0.71 \%) \\
\text { Per 100 patient-years } & 0.33 & 0.30
\end{array}
$$

Cardiovascular events, ADRs

\begin{tabular}{lll}
$N(\%)$ & $18(0.17 \%)$ & $14(0.13 \%)$ \\
Per 100 patient-years & 0.07 & 0.05 \\
Malignant tumours, AEs & & \\
$N(\%)$ & 111 & $111(1.04 \%)$ \\
& $(1.04 \%)$ & \\
Per 100 patient-years & 0.44 & 0.44 \\
Malignant tumours, ADRs & & \\
$N(\%)$ & $27(0.25 \%)$ & $27(0.25 \%)$ \\
Per 100 patient-years & 0.11 & 0.11 \\
\hline
\end{tabular}

Table 2 continued

\begin{tabular}{lll}
\hline Patients analysed for safety & 10,696 & \\
\cline { 2 - 3 } & All ADRs & $\begin{array}{l}\text { Serious } \\
\text { ADRs }\end{array}$ \\
\hline
\end{tabular}

Other ADRs (in $\geq 10$ patients)

Dizziness, $N(\%)$ $11(0.10 \%) \quad 0$

Values are number (\%) of patients. ADRs were defined as adverse events for which a causal relationship with teneligliptin could not be excluded (i.e. related or unknown) $A E$ adverse event, $A D R$ adverse drug reaction

none in two patients. Supplemental Table 6 shows the outcomes of ADRs and AEs of special interest.

Among 220 patients with a dose increase to $40 \mathrm{mg}, 13$ patients (5.91\%) experienced 16 ADRs and 3 patients (1.36\%) experienced 4 serious ADRs. The prescribing physician reported the causal relationship of 12 of 16 ADRs with teneligliptin as unknown. The ADRs in 13 patients were hepatic function abnormal, which occurred in two patients, and pancreatic carcinoma, lung neoplasm malignant, anaemia, diabetes mellitus, dementia Alzheimer's type, atrial flutter, constipation, liver function test increased, alopecia areata, pemphigoid, myalgia, gynaecomastia, alanine aminotransferase increased and aspartate aminotransferase increased in one patient each. The serious ADRs were hepatic function abnormal, pancreatic carcinoma, lung neoplasm malignant and pemphigoid.

There were small but significant changes in body weight $(-0.86 \pm 4.37 \mathrm{~kg}, \quad n=3039$, $p<0.001)$, triglycerides $(-15.1 \pm 112.0 \mathrm{mg} /$ $\mathrm{dL}, n=3377, p<0.001)$ and LDL-cholesterol $(-6.8 \pm 39.3 \mathrm{mg} / \mathrm{dL}, \quad n=3009, \quad p<0.001)$ between baseline and 3 years (Supplemental Table 7). There was a non-significant change in HDL-cholesterol over this period $(0.3 \pm 13.4$ $\mathrm{mg} / \mathrm{dL}, n=3114, p=0.211$ ).

\section{Stratified Analyses by Renal Function}

The incidences of all ADRs and serious ADRs tended to be greater in the patients in the G4 and G5 subgroups than in the G1 subgroup (Table 3). Among patients on dialysis, ADRs 


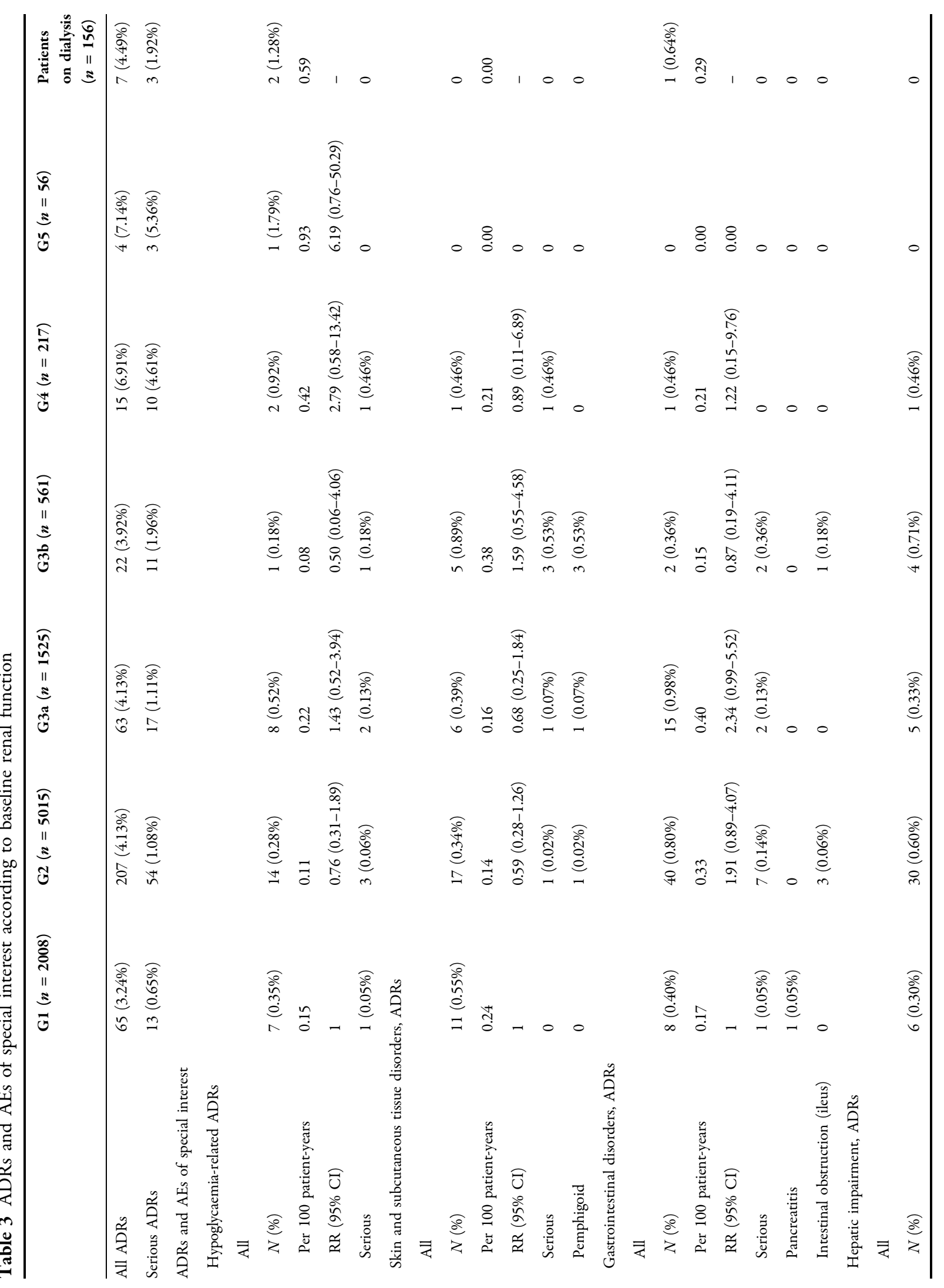




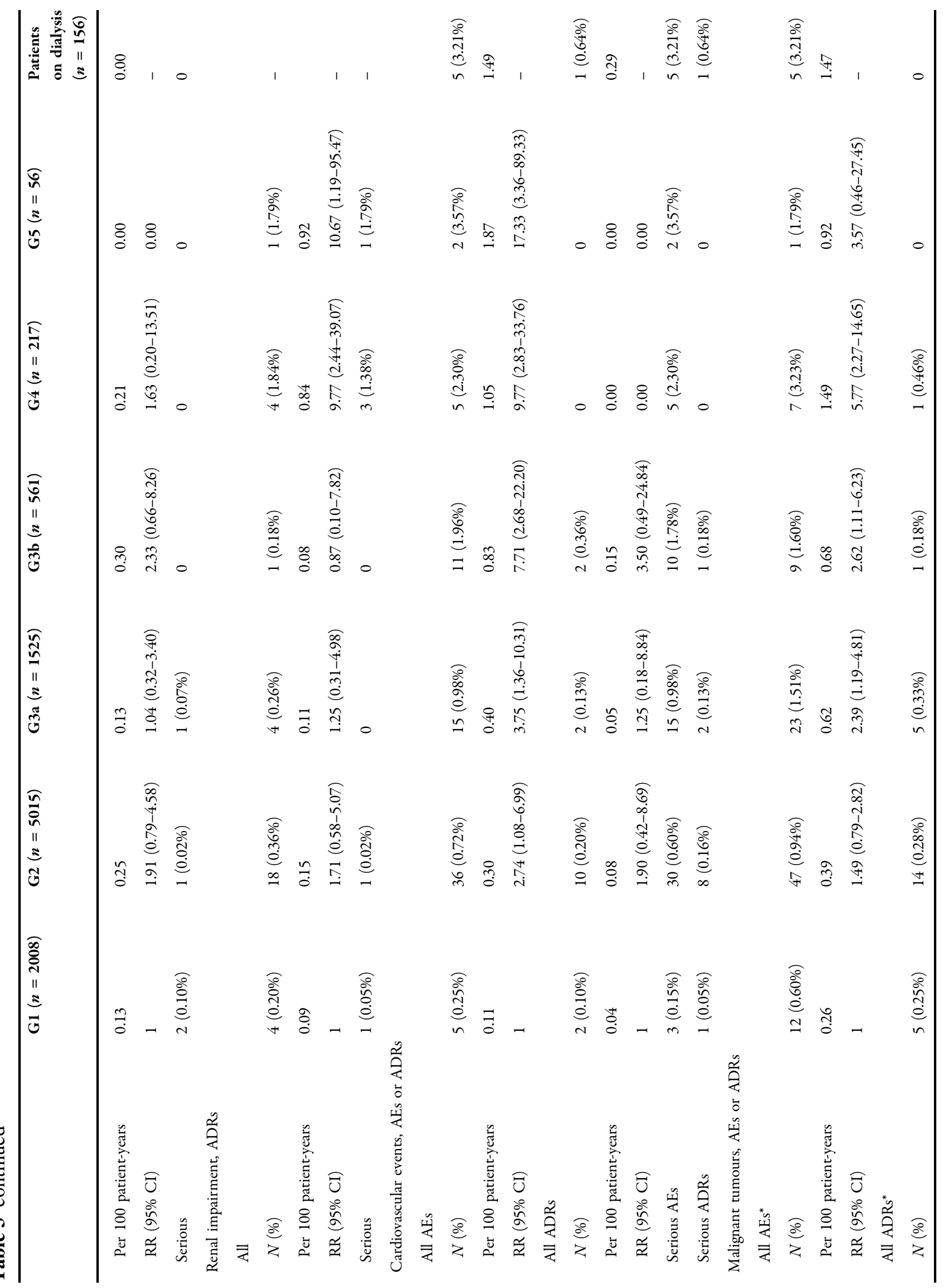




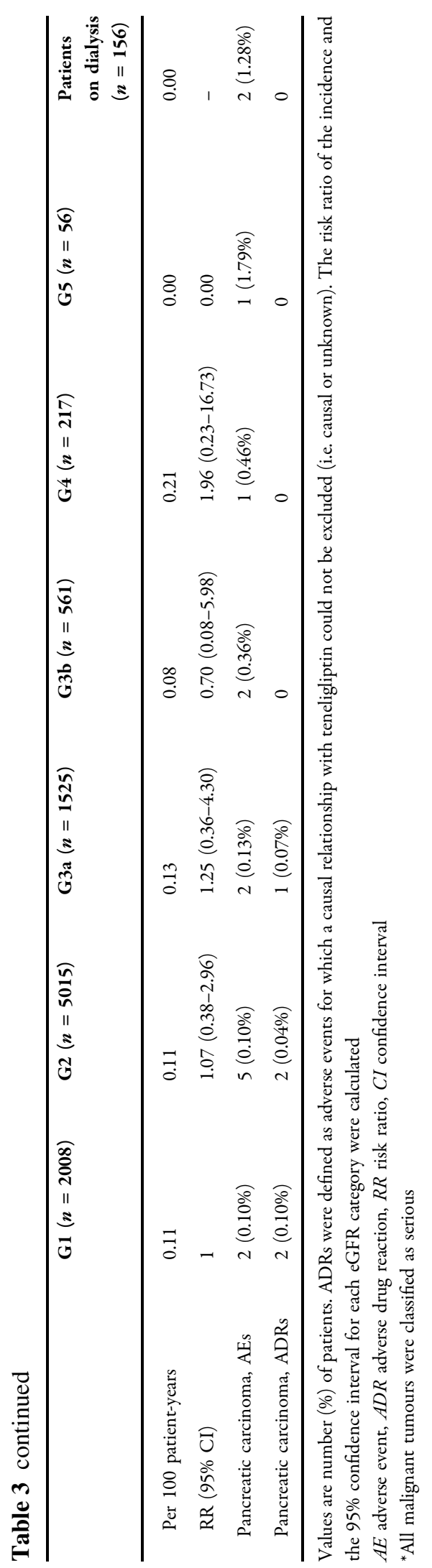

occurred in $4.49 \%$ and serious ADRs occurred in $1.92 \%$. Of 29 events of ADRs reported in the 19 patients in the G4 and G5 subgroups, 7 events were considered to be possibly related to teneligliptin, while the causal relationship between teneligliptin and the ADRs in 22 events was assessed as unknown and 15 events were attributed to other causes (e.g. comorbidity or concomitant agent) by the prescribing physician. There were no significant differences in the incidences of special interest ADRs across the eGFR subgroups, excluding renal impairment. The incidences of ADRs related to renal impairment tended to be greater in the patients in the G4 and G5 subgroups than in the G1 subgroup. The renal impairment as ADRs were reported in five patients in these subgroups; blood creatinine increased, hypoalbuminaemia, hyponatraemia, renal impairment and haemodialysis. Six patients with advanced stages of renal impairment (eGFR $<45 \mathrm{ml} / \mathrm{min} /$ $1.73 \mathrm{~m}^{2}$ [G3b-G5] or patients on dialysis) experienced hypoglycaemia, including serious hypoglycaemia in two patients. Among 41 patients with eGFR $<45 \mathrm{ml} / \mathrm{min} / 1.73 \mathrm{~m}^{2}$ or on dialysis at baseline whose teneligliptin dose was increased from 20 to $40 \mathrm{mg}$, two experienced an ADR (hepatic function abnormal, dementia of Alzheimer's type). As indicated in Fig. 2, the median eGFR decreased at 6 months in patients classified as G1 and G2, but remained stable thereafter. There were no clear changes in patients classified as G3a-G5.

\section{Efficacy}

\section{Overall Population}

As shown in Fig. 3, there were significant reductions in both HbA1c and FBG from baseline through to 6-36 months, with reductions in HbA1c of $-0.70 \pm 1.36 \% \quad(n=5027$, $p<0.001)$ and FBG of $-19.8 \pm 48.2 \mathrm{mg} / \mathrm{dL}$ $(n=1096, p<0.001)$ at 3 years. Among patients with HbA1c data at 3 years and whose HbA1c was $\geq 7.0 \%$ at baseline, $46.9 \%(n=1612 / 3440)$ achieved HbA1c $<7 \%$ at 3 years. Among patients whose teneligliptin dose was increased from 20 to $40 \mathrm{mg}$ during the observation, their baseline HbA1c was $8.26 \pm 1.95 \% \quad(n=152)$, 


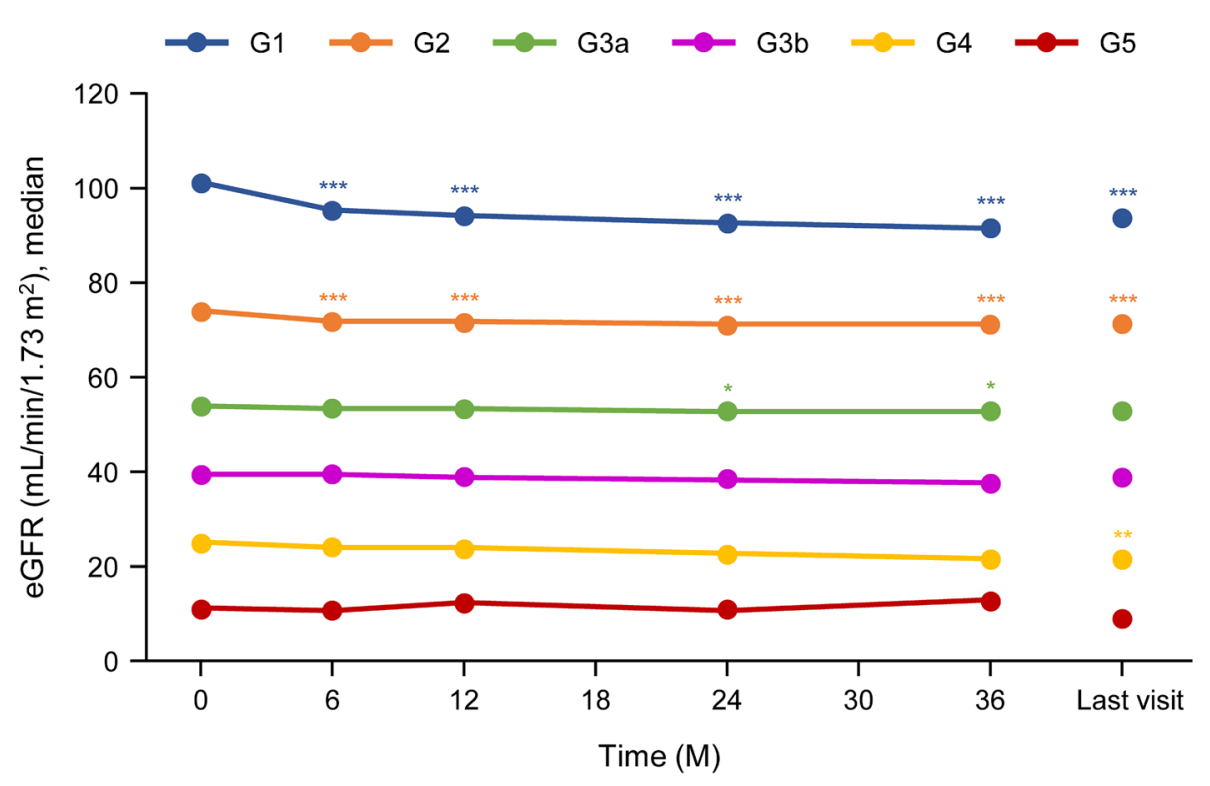

\begin{tabular}{lccccccc}
\hline $\begin{array}{c}\text { Baseline eGFR } \\
\text { category, } \\
\mathrm{mL} / \mathrm{min} / 1.73 \mathrm{~m}^{2}\end{array}$ & $0 \mathrm{M}$ & $6 \mathrm{M}$ & $12 \mathrm{M}$ & $24 \mathrm{M}$ & $36 \mathrm{M}$ & Last visit & $\begin{array}{c}\text { Median change } \\
\text { at 36 M }\end{array}$ \\
\cline { 2 - 7 } $\mathrm{G} 1, \geq 90$ & 1,602 & 1,179 & 1,026 & 832 & 663 & 1,602 & $-9.61(-19.40,0.00)$ \\
\hline $\mathrm{G} 2,60$ to $<90$ & 4,034 & 3,058 & 2,723 & 2,239 & 1,924 & 4,034 & $-2.73(-8.98,3.47)$ \\
\hline $\mathrm{G} 3 \mathrm{a}, 45$ to $<60$ & 1,252 & 954 & 832 & 699 & 567 & 1,252 & $-0.86(-6.04,4.45)$ \\
\hline $\mathrm{G} 3 \mathrm{~b}, 30$ to $<45$ & 483 & 390 & 357 & 287 & 229 & 483 & $-1.03(-6.74,4.68)$ \\
\hline $\mathrm{G} 4,15$ to $<30$ & 189 & 161 & 130 & 102 & 69 & 189 & $-1.78(-6.06,4.64)$ \\
\hline $\mathrm{G} 5,<15$ & 44 & 37 & 24 & 20 & 15 & 44 & $0.70(-3.98,60.22)$ \\
\hline
\end{tabular}

Fig. 2 Changes in eGFR according to grade of renal impairment in patients, excluding patients on dialysis. ${ }^{*} p<0.05,{ }^{* *} p<0.01, \quad{ }^{* * *} p<0.001$ vs baseline by

$7.88 \pm 1.42 \%$ at the time of the dose increase $(n=160)$ and $7.56 \pm 1.40 \%$ at the last visit in the dose-increase period $(n=160)$. The mean changes were $-0.69 \pm 1.91 \%(n=152)$ from baseline and $-0.33 \pm 1.39 \%(n=160)$ from the time of the dose increase to the last visit after the dose increase.

\section{Stratified Analyses by Renal Function}

As illustrated in Fig. 4, there were significant reductions in HbA1c levels over 3 years in subgroups G1-G4. HbA1c decreased or tended to decrease in subgroup G5, although the reduction in HbA1c was not significant after 1 year of treatment. In order to adjust for differences in baseline HbA1c, the LS mean change in HbA1c
Wilcoxon signed rank test. eGFR estimated glomerular filtration rate, $G$ grade, $M$ months

was calculated for all six eGFR subgroups. With adjustment, the LS mean changes in HbA1c were $-0.76 \%$ to $-0.66 \%$ in G1-G5 at 3 years, and there were no significant differences in the changes in HbA1c among the six subgroups $(p=0.333$, Fig. 4a). Among patients on dialysis, glycated albumin decreased significantly by $2.92 \pm 4.78 \%$ from baseline to 3 years $(n=41$, $p<0.001$; Fig. 4b).

\section{DISCUSSION}

The RUBY post-marketing surveillance was designed with the objectives of accumulating data on the safety and efficacy of long-term 

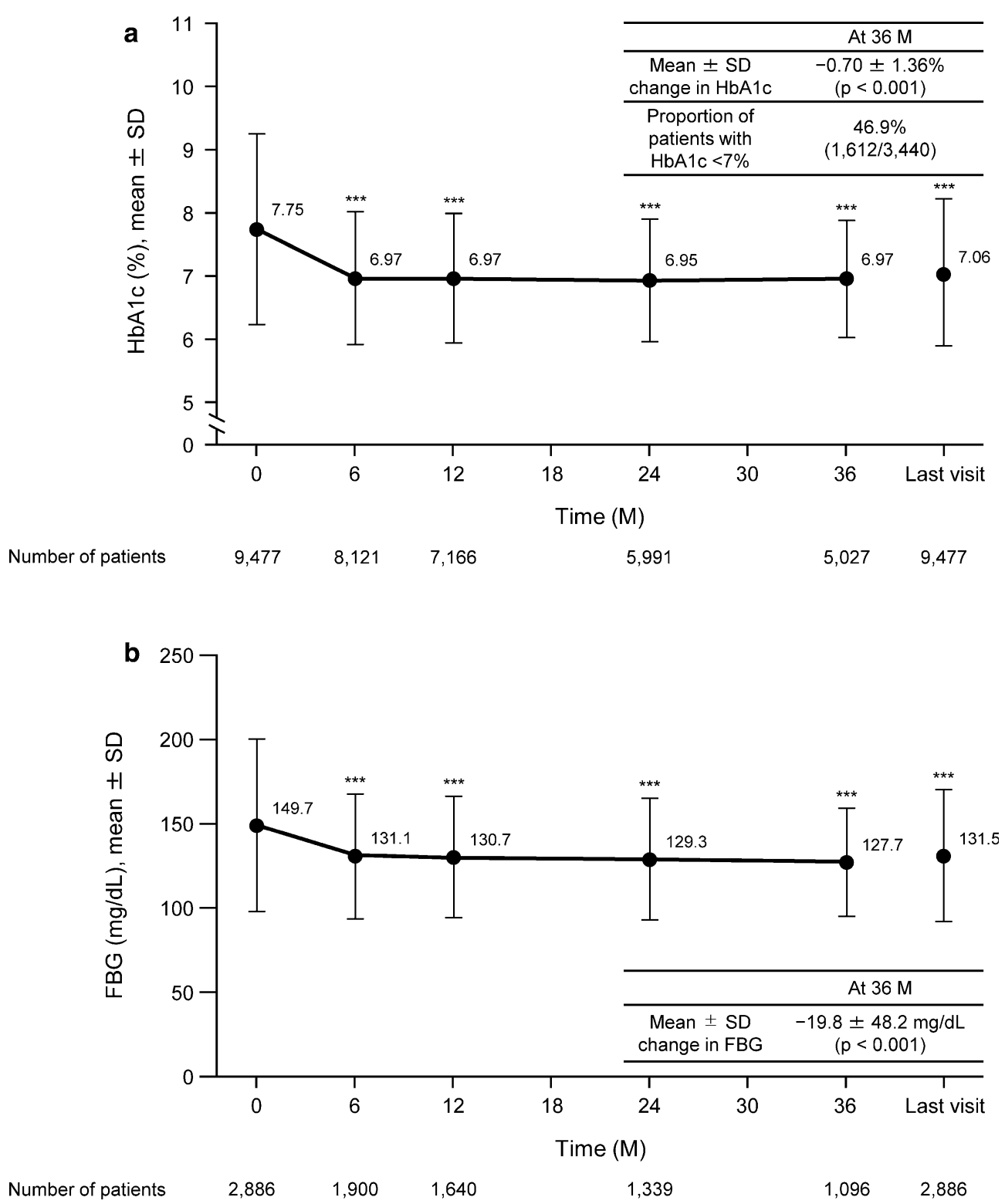

Fig. 3 Changes in HbAlc $(\mathbf{a})$ and FBG $(\mathbf{b})$ over time. ${ }^{* * *} p<0.001$ vs baseline by paired $t$ test. HbAlc haemoglobin Alc, $F B G$ fasting blood glucose, $M$ months, $S D$ standard deviation

treatment with teneligliptin in patients with T2DM in real-world clinical settings in Japan. Post-marketing surveillance and observational studies have also been published for a number of other DPP4 inhibitors, including linagliptin [30, 31], sitagliptin [32-34], vildagliptin [35], omarigliptin [36] and anagliptin [37, 38]. Most of these reports enrolled several thousand patients and some were based on interim analyses. In our present report, we analysed the safety and efficacy data of more than 10,000 patients treated with teneligliptin for up to 3 years.

\section{Safety in Overall Population}

This surveillance revealed that the incidence of any ADRs in teneligliptin-treated patients was $3.85 \%$ and serious ADRs in $1.09 \%$. Of note, the overall rate of ADRs did not exceed the rates 


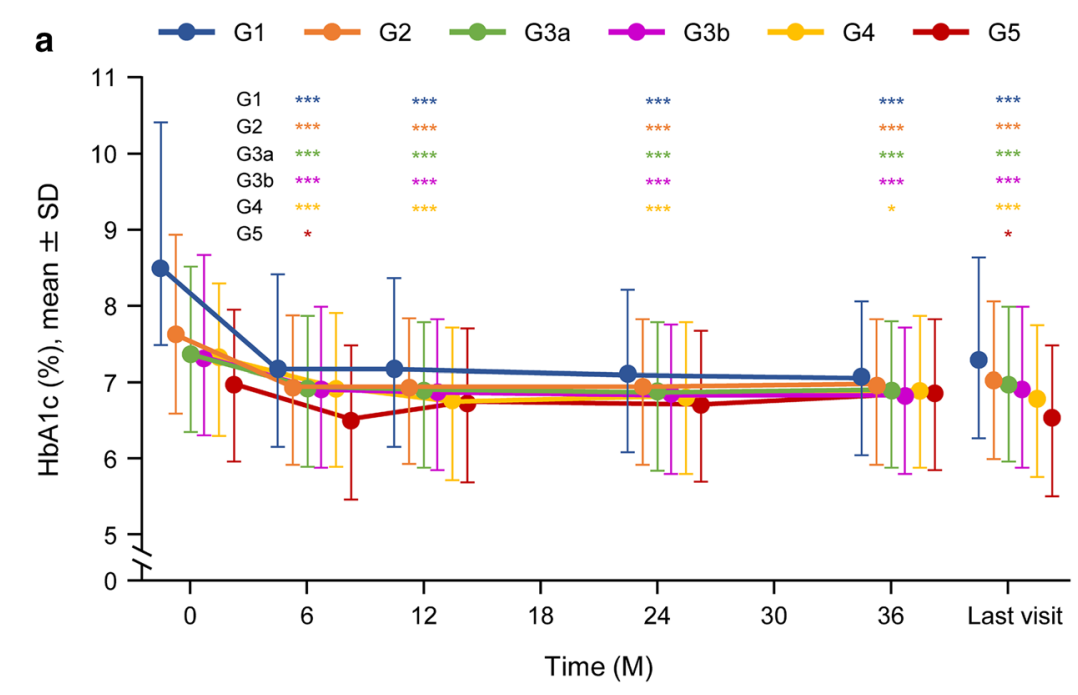

\begin{tabular}{lcccccccc}
\hline $\begin{array}{c}\text { Baseline eGFR } \\
\text { category, } \\
\mathrm{mL} / \mathrm{min} / 1.73 \mathrm{~m}^{2}\end{array}$ & $0 \mathrm{M}$ & $6 \mathrm{M}$ & $12 \mathrm{M}$ & $24 \mathrm{M}$ & $36 \mathrm{M}$ & Last visit & $\begin{array}{c}\text { LS mean } \\
\text { change } \pm \text { SE } \\
\text { at } 36 \mathrm{M}\end{array}$ & $\begin{array}{c}\text { Proportion of } \\
\text { patients with } \\
\mathrm{HbA1c}<7 \% \\
\text { at } 36 \mathrm{M}\end{array}$ \\
\hline $\mathrm{G} 1, \geq 90$ & 1,814 & 1,532 & 1,330 & 1,098 & 908 & 1,814 & $-0.76 \pm 0.03$ & $\begin{array}{c}45.5 \% \\
(331 / 727)\end{array}$ \\
\hline $\mathrm{G} 2,60$ to $<90$ & 4,572 & 3,951 & 3,528 & 3,006 & 2,562 & 4,572 & $-0.68 \pm 0.02$ & $\begin{array}{c}46.3 \% \\
(809 / 1,748)\end{array}$ \\
\hline $\mathrm{G} 3 \mathrm{a}, 45$ to $<60$ & 1,393 & 1,196 & 1,068 & 881 & 744 & 1,393 & $-0.68 \pm 0.03$ & $\begin{array}{c}49.8 \% \\
(222 / 446)\end{array}$ \\
\hline $\mathrm{G} 3 \mathrm{~b}, 30$ to $<45$ & 521 & 455 & 407 & 336 & 272 & 521 & $-0.72 \pm 0.05$ & $\begin{array}{c}55.6 \% \\
(80 / 144)\end{array}$ \\
\hline $\mathrm{G} 4,15$ to $<30$ & 187 & 170 & 145 & 112 & 80 & 187 & $-0.67 \pm 0.10$ & $\begin{array}{c}44.2 \% \\
(19 / 43)\end{array}$ \\
\hline $\mathrm{G} 5,<15$ & 43 & 35 & 23 & 19 & 14 & 43 & $-0.66 \pm 0.23$ & $\begin{array}{c}20.0 \% \\
(1 / 5)\end{array}$ \\
\hline
\end{tabular}

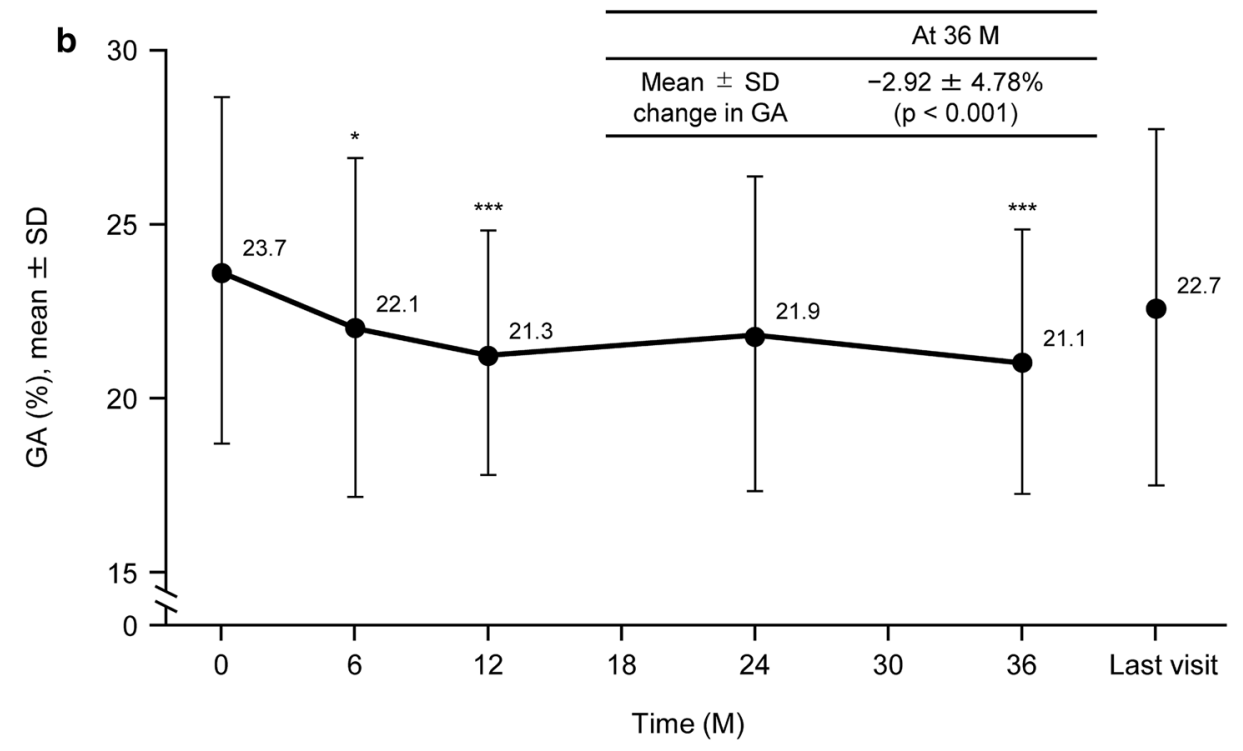

$\begin{array}{lllllll}\text { Number of patients } & 86 & 76 & 67 & 52 & 41 & 86\end{array}$ 
4Fig. 4 a Changes in HbAlc over time according to grade of renal impairment in patients, excluding patients on dialysis. b Changes in glycated albumin over time in patients on dialysis. ${ }^{*} p<0.05,{ }^{* *} p<0.01,{ }^{* * *} p<0.001$ vs baseline by paired $t$ test. $G$ grade, $G A$ glycated albumin, $H b A 1 c$ haemoglobin A1c, $L S$ least squares, $M$ months, $S D$ standard deviation, $S E$ standard error

observed in clinical trials $(9.48 \%$ of 1645 patients) [23] or over 1 year in clinical trials (6.7-18.9\%) [13] in Japan. The safety profile of teneligliptin in this surveillance was generally similar to those reported for other DPP4 inhibitors [30-36].

Gastrointestinal disorders $(0.68 \%)$ were the most common classes of ADR, although most patients recovered or were recovering. Intestinal obstruction (ileus) was reported in four patients $(0.04 \%)$ in this surveillance, and did not exceed the incidence $(0.1 \%)$ reported in clinical trials of teneligliptin [23]. However, as mentioned for intestinal obstruction in the teneligliptin package insert [23], administration of teneligliptin should be discontinued and appropriate treatments should be taken if any abnormalities occur such as severe constipation, abdominal distension, persistent abdominal pain or vomiting.

The incidence of hypoglycaemia-related ADRs was $0.36 \%$. All of the patients with serious hypoglycaemia were those who were also taking an insulin or sulfonylurea, in whom the risk of hypoglycaemia is supposed to be increased. Therefore, careful management is required to avoid hypoglycaemia when using these antidiabetic agents together with a DPP4 inhibitor.

The incidence of hepatic impairment-related ADRs was $0.44 \%$ in the RUBY surveillance. The risk of hepatic impairment of DPP4 inhibitors was pointed out after the launch of teneligliptin by the Pharmaceuticals and Medical Devices Agency of Japan. The package insert of teneligliptin was revised in 2014, as with other DPP4 inhibitors, and alerts have been issued [23].

The incidence of ADRs of skin and subcutaneous tissue disorders was $0.41 \%$ in this surveillance. Pemphigoid was added to the package insert for teneligliptin during the observation period [23], having emerged as a possible ADR associated with DPP4 inhibitors, including teneligliptin [39-42]. In this surveillance, pemphigoid was reported as an ADR in five patients $(0.05 \%)$. The frequency in this surveillance is similar to that of $0.0859 \%$ in an earlier single-centre study in Japan of 9304 patients treated with other DPP4 inhibitors [43]. Other studies have revealed that the risk of pemphigoid, including epidermolysis bullosa acquisita, is also increased in older people [44] and in people with the $H L A-D Q B 1{ }^{*} 03: 01$ genotype [45]. Like these previous reports, many of the patients with pemphigoid in RUBY were elderly. As described in the package insert [23], it is important for the prescribing doctor to consult a dermatologist and take appropriate action in patients who develop blisters or sores, e.g., when taking teneligliptin.

In this surveillance, cardiovascular events were reported as AEs in 85 patients $(0.79 \%$; 0.33 per 100 patient-years), with ADRs in 18 patients $(0.17 \%)$. In the J-DOIT3 (Japan Diabetes Optimal Integrated Treatment study for 3 major risk factors of cardiovascular diseases) study [46], which had a median follow-up of 8.5 years, cardiovascular events occurred in 97 of 1271 patients who received conventional therapy, with coronary events in $4.3 \%$ and cerebrovascular events in 3.3\%. Meanwhile, in the observational Japan Diabetes Complications Study [47] of 1771 patients with T2DM but no history of cardiovascular complications with a median follow-up of 7.86 years, the incidences of coronary heart disease, stroke, myocardial infarction and brain infarction were 9.59, 7.45, 3.84 and 6.29 per 1000 patient-years, respectively. Although direct comparisons are not possible because of the different definitions of cardiovascular events, the results of these earlier studies suggest that the rates of $\mathrm{AE}$ of cardiovascular events in the present surveillance are within (or below) the expected rate for Japanese patients with T2DM.

Fifteen cases of pancreatic carcinoma were reported in the RUBY surveillance. The pooled analysis showed that diabetes was associated with an increased risk of pancreatic carcinoma (HR 1.85, 95\% CI 1.46-2.34) in Japan [48]. Based on the prevalence of pancreatic carcinoma in the Japanese general population [49], 
the expected number of pancreatic carcinoma, adjusted for age, diabetes $[48,50]$ and duration of observation, in RUBY was 25.62. The standardised incidence ratio, calculated ratio of the observed number to the expected number, was 0.59 (95\% CI 0.34-0.99). Therefore, teneligliptin is not considered to increase the risk of pancreatic carcinoma.

Dizziness, an ADR that was not prospectively defined as an ADR of special interest, occurred in $0.1 \%$ of patients in this surveillance. This is identical to the rate of $0.1 \%$ derived from clinical trials for up to 1 year [23]. This suggests that the rate of dizziness is not increased among patients prescribed teneligliptin in real-world settings.

We also observed a significant change in body weight after treatment with teneligliptin, although this may be a marginal change in clinical practice. DPP4 inhibitors are considered to have a neutral effect on body weight $[4,6]$, so our results are consistent with previous studies.

\section{Safety in Patients with Renal Impairment}

In the present surveillance, the incidences of overall ADRs, particularly for ADRs related to renal impairment, and serious ADRs were numerically greater in the G4 and G5 subgroups than in the G1 subgroup. Patients with renal impairment are generally more prone to AEs due to multiple factors including comorbidities and the need for polypharmacy [51]. Indeed, in RUBY, the rate of comorbidities was higher in patients with advanced renal impairment. We must acknowledge possible limitations of this analysis, including the varying numbers of patients in each subgroup, and no matched control group for each stage of renal impairment as we previously reported $[24,25]$. Nevertheless, our findings indicate the importance of carefully monitoring these patients.

The risk of hypoglycaemia, for example, is also increased in patients with renal impairment for a number of reasons, including reduced insulin clearance and impaired renal gluconeogenesis $[8,52,53]$. Hypoglycaemia in patients with renal impairment mostly occurred in patients using teneligliptin in combination with other antidiabetic agents associated with hypoglycaemia (insulin, sulfonylurea or glinide), highlighting the need for caution when prescribing teneligliptin in combination with these agents in patients with renal impairment.

In the G1 and G2 subgroups, eGFR decreased at 6 months but remained constant thereafter, whereas the median eGFR in patients with renal impairment did not change markedly over the 3-year period. Some DPP4 inhibitors were reported to improve the albumin to creatinine ratio without an improvement in eGFR [54]. Although the degree of change in eGFR varied among patients and between time points in the RUBY surveillance, we believe further studies are needed to evaluate the effects of teneligliptin on the kidneys.

\section{Efficacy of Teneligliptin}

We also assessed the efficacy of teneligliptin in real-world settings and observed significant improvements in $\mathrm{HbA1c}$ and FBG that were apparent within 6 months of treatment and maintained for up to 3 years. These findings are similar to those reported for teneligliptin showing reductions in HbA1c over 52 weeks in clinical trials [22] and in other reports for linagliptin [30, 31], sitagliptin [32-34], vildagliptin [35], omarigliptin [36] and anagliptin [37, 38] used for varying lengths of time in Japanese patients with T2DM.

Another objective of this analysis was to examine the efficacy of teneligliptin in the population of six eGFR categories and patients on dialysis. Here, we found reductions in HbA1c from baseline through to 3 years in the G1-G4 subgroups. HbA1c decreased or tended to decrease in the G5 subgroup, although the reduction in $\mathrm{HbA1c}$ was not significant after 1 year of treatment, which may be due to the low baseline value and/or the small number of patients. With adjustment for differences in baseline HbA1c, the LS mean changes in HbA1c were $-0.76 \%$ to $-0.66 \%$ in G1-G5 at 3 years, and there were no significant differences in the changes in HbA1c among the six subgroups at 3 years. A significant reduction in glycated albumin occurred in patients on dialysis. These 
results are consistent with those of prior studies for teneligliptin in patients with T2DM and renal impairment [55] or patients with T2DM on haemodialysis $[56,57]$.

\section{Teneligliptin Dose Increase}

Additionally, we wish to discuss the safety and efficacy profiles in patients whose teneligliptin dose was increased to $40 \mathrm{mg}$. In this surveillance, we found that the frequency of ADRs and serious ADRs in patients prescribed $40 \mathrm{mg}$ /day were similar to the corresponding values in the overall population, and the values reported in a pooled analysis of 204 patients who underwent a teneligliptin dose increase in phase III clinical trials [58] (4.9\% before the dose increase and $7.4 \%$ after the dose increase). Although hypoglycaemia was the most frequent ADR in that pooled analysis, its frequency was not increased after the dose increase. In terms of efficacy in RUBY, HbA1c decreased from the time of the dose increase with a mean change of $-0.33 \%$. In the above analysis of phase III clinical trials, 108 of 204 patients showed an HbA1c reduction after the dose increase, with a mean change in HbA1c of $-0.50 \%$ in these patients [58]. These results suggest that increasing the dose of teneligliptin to $40 \mathrm{mg}$ may be helpful to improve HbA1c in patients with an insufficient improvement in glycaemic control with $20 \mathrm{mg}$ teneligliptin.

\section{Limitations}

Some possible limitations deserve mention, including the absence of a control group and that some patients changed their concomitant agents or lifestyle modifications during the observation period, which may contribute to safety and efficacy. The impact of changes in these therapies or lifestyle modifications on safety and efficacy could not be assessed. We must also acknowledge the possibility of reporting bias in that some AEs and ADRs may not have been reported by the patient or prescribing physician, or that the physician may have incorrectly rejected a possible causal relationship with teneligliptin, which may result in under-reporting of some AEs and ADRs. Laboratory test data were also unavailable for a substantial number of patients, although this is a common problem in post-marketing surveillance and studies of clinical practice where some laboratory tests may not be performed routinely or at the time points suitable for recording in the case report forms. In Japan, it is important to note that FBG is not routinely recorded. It is also possible that some of the values entered by the prescribing physician were medically unreasonable (i.e. significantly higher or significantly lower than normal, or physiologically improbable). Despite these limitations, this surveillance has several strengths, notably the large sample size, despite about one-third of patients discontinuing teneligliptin for any reason, and the long duration (median duration of exposure of 1096 days). These strengths allowed us to obtain important insights into the long-term use of teneligliptin in real-world settings.

\section{CONCLUSIONS}

The safety profile of teneligliptin in this postmarketing surveillance of patients with T2DM in long-term, real-world clinical practice did not differ markedly from the established safety profiles of teneligliptin or other DPP4 inhibitors. The surveillance also confirmed that the efficacy of teneligliptin is maintained for up to 3 years in real-world settings, supporting its long-term use. The safety and efficacy of teneligliptin were also maintained in patients with renal impairment and in patients on dialysis.

\section{ACKNOWLEDGEMENTS}

We are grateful to all physicians and patients involved in this post-marketing surveillance, K. Yoshida (Mitsubishi Tanabe Pharma Corporation) who managed the collection of the case report forms, and M. Ueno (former employee of Mitsubishi Tanabe Pharma Corporation) for insightful discussions. 
Funding. The surveillance was funded by Mitsubishi Tanabe Pharma Corporation and Daiichi Sankyo Co., Ltd. Mitsubishi Tanabe Pharma Corporation also funded the journal's rapid service and open access fee.

Medical Writing Assistance. The authors thank Nicholas D. Smith (EMC K.K.) for medical writing support, which was funded by Mitsubishi Tanabe Pharma Corporation.

Authorship. All named authors meet the International Committee of Medical Journal Editors (ICMJE) criteria for authorship for this article, take responsibility for the integrity of the work as a whole, and have given their approval for this version to be published.

Author Contributions. T. Kadowaki, M. Haneda, and H. Ito contributed to data interpretation and provided medical advice. K. Sasaki and Y. Yamada contributed to the conception of the surveillance and data interpretation. M. Matsukawa contributed to the analyses and data interpretation. All authors contributed to manuscript development.

Disclosures. Takashi Kadowaki reports grants and personal fees from Astellas Pharma Inc., MSD Corporation, Ono Pharmaceutical Co., Ltd., Takeda Pharmaceutical Co., Ltd., Mitsubishi Tanabe Pharma Corporation, Eli Lilly Japan K.K., Novo Nordisk Pharma Ltd., Kissei Pharmaceutical Co., Ltd., Daiichi Sankyo Co., Ltd., Taisho Pharma Co., Ltd., Sumitomo Dainippon Pharma Co., Ltd., and Sanofi K.K.; personal fees from AstraZeneca K.K., Kowa Pharmaceutical Co., Ltd., Nippon Boehringer Ingelheim Co., Ltd., Novartis Pharma K.K., Bayer Yakuhin Ltd., Sanwa Kagaku Kenkyusho Co., Ltd., Kyowa Kirin Co., Ltd., Nipro Corporation, Medical View Co., Ltd., Musashino Foods Corporation, Medtronic Sofamor Danek Co., Ltd., Johnson \& Johnson Co., Ltd., Terumo Co., Ltd., Medical Review Co., Ltd., Medscape Education, Abbott Japan Co., Ltd., Cosmic Corporation Co., Ltd., and FUJIFILM Toyama Chemical Co., Ltd.; funding for endowed chair from AstraZeneca Co., Ltd., MSD Corporation, Ono Pharmaceutical Co., Ltd., Kowa
Pharmaceutical Co., Ltd., Takeda Pharmaceutical Co., Ltd., Mitsubishi Tanabe Pharma Corporation, Nippon Boehringer Ingelheim Co., Ltd., Novo Nordisk Pharma Ltd., and Asahi Mutual Life Insurance Co.; contract research funding from AstraZeneca Co., Ltd. and Takeda Pharmaceutical Co., Ltd.; and joint research funding from other from Daiichi Sankyo Co., Ltd.

Masakazu Haneda has received clinical research grants from Novo Nordisk Pharma Ltd., Ono Pharmaceutical Co., Ltd., Shionogi \& Co., Ltd., and Johnson \& Johnson Co., Ltd.; and personal fees from Astellas Pharma Inc., Taisho Pharma Co., Ltd., Mitsubishi Tanabe Pharma Corporation, Nippon Boehringer Ingelheim Co., Ltd., Taisho Pharma Co., Ltd., Kowa Pharmaceutical Co., Ltd., Ono Pharmaceutical Co., Ltd., MSD Corporation, Novartis Pharma K.K., and Novo-Nordisk Pharma Ltd.

Hiroshi Ito has received grants and personal fees from Mitsubishi Tanabe Pharma Corporation and Daiichi Sankyo Co., Ltd.

Kazuyo Sasaki, Miyuki Matsukawa, and Yuka Yamada are employees of Mitsubishi Tanabe Pharma Corporation.

Compliance with Ethics Guidelines. The surveillance protocol was approved by the Ministry of Health, Labour and Welfare of Japan, and was performed by Mitsubishi Tanabe Pharma Corporation in accordance with the Japanese ministry directive on Good Post-marketing Study Practice (GPSP). The surveillance used anonymous data collected in clinical practice in Japan. In accordance with Japanese regulations for post-marketing surveillance, it is not necessary to obtain informed consent from patients. RUBY was registered on the Japan Pharmaceutical Information Center clinical trials database (Japic CTI-153047).

Data Availability. The datasets generated and/or analysed during the current study are not publicly available to protect individual patient confidentiality, but are available from the corresponding author on reasonable request. 
Open Access. This article is licensed under a Creative Commons Attribution-NonCommercial 4.0 International License, which permits any non-commercial use, sharing, adaptation, distribution and reproduction in any medium or format, as long as you give appropriate credit to the original author(s) and the source, provide a link to the Creative Commons licence, and indicate if changes were made. The images or other third party material in this article are included in the article's Creative Commons licence, unless indicated otherwise in a credit line to the material. If material is not included in the article's Creative Commons licence and your intended use is not permitted by statutory regulation or exceeds the permitted use, you will need to obtain permission directly from the copyright holder. To view a copy of this licence, visit http://creativecommons.org/licenses/by$\mathrm{nc} / 4.0 /$.

\section{REFERENCES}

1. Guariguata L, Whiting DR, Hambleton I, Beagley J, Linnenkamp U, Shaw JE. Global estimates of diabetes prevalence for 2013 and projections for 2035 . Diabetes Res Clin Pract. 2014;103(2):137-49. https://doi.org/10.1016/j.diabres.2013.11.002.

2. Ministry of Health, Labour and Welfare. National Health and Nutrition Survey in Japan 2016; 2016. https://www.mhlw.go.jp/file/04-Houdouhappyou10904750-Kenkoukyoku-Gantaisakukenkouzoush inka/kekkagaiyou_7.pdf (in Japanese). Accessed 17 Sept 2019.

3. Nitta K, Masakane S, Hanafusa N, et al. 2017 Annual dialysis data report, JSDT Renal Data Registry. Nihon Toseki Igakkai Zasshi. 2018;51(12):699-766. https://doi.org/10.4009/jsdt.51.699 (in Japanese).

4. American Diabetes Association. Glycemic targets: standards of medical care in diabetes-2019. Diabetes Care. 2019;42(Suppl 1):S61-70. https://doi.org/10. 2337/dc19-s006.

5. Araki E, Haneda M, Kasuga M, et al. New glycemic targets for patients with diabetes from the Japan Diabetes Society. J Diabetes Investig. 2017;8(1): 123-5. https://doi.org/10.1111/jdi.12600.

6. Davies MJ, D'Alessio DA, Fradkin J, et al. Management of hyperglycaemia in type 2 diabetes, 2018. A consensus report by the American Diabetes
Association (ADA) and the European Association for the Study of Diabetes (EASD). Diabetologia. 2018;61(12):2461-98. https://doi.org/10.1007/ s00125-018-4729-5.

7. Avogaro A, Schernthaner G. Achieving glycemic control in patients with type 2 diabetes and renal impairment. Acta Diabetol. 2013;50(3):283-91. https://doi.org/10.1007/s00592-012-0442-x.

8. Tuttle KR, Bakris GL, Bilous RW, et al. Diabetic kidney disease: a report from an ADA Consensus Conference. Am J Kidney Dis. 2014;64(4):510-33. https://doi.org/10.1053/j.ajkd.2014.08.001.

9. Seino Y, Kuwata H, Yabe D. Incretin-based drugs for type 2 diabetes: focus on East Asian perspectives. J Diabetes Investig. 2016;7(Suppl 1):102-9. https:// doi.org/10.1111/jdi.12490.

10. Cho YM. Incretin physiology and pathophysiology from an Asian perspective. J Diabetes Investig. 2015;6(5):495-507. https://doi.org/10.1111/jdi. 12305.

11. Yabe D, Seino Y, Fukushima M, Seino S. Beta cell dysfunction versus insulin resistance in the pathogenesis of type 2 diabetes in East Asians. Curr Diab Rep. 2015;15(6):602. https://doi.org/10.1007/ s11892-015-0602-9.

12. Kim YG, Hahn S, Oh TJ, Kwak SH, Park KS, Cho YM. Differences in the glucose-lowering efficacy of dipeptidyl peptidase- 4 inhibitors between Asians and non-Asians: a systematic review and metaanalysis. Diabetologia. 2013;56(4):696-708. https:// doi.org/10.1007/s00125-012-2827-3.

13. Ceriello A, De Nigris V, Iijima H, Matsui T, Gouda M. The unique pharmacological and pharmacokinetic profile of teneligliptin implications for clinical practice. Drugs. 2019;979(7):733-50. https:// doi.org/10.1007/s40265-019-01086-0.

14. Eto T, Inoue S, Kadowaki T. Effects of once-daily teneligliptin on 24-h blood glucose control and safety in Japanese patients with type 2 diabetes mellitus: a 4-week, randomized, double-blind, placebo-controlled trial. Diabetes Obes Metab. 2012;14(11):1040-6. https://doi.org/10.1111/j. 1463-1326.2012.01662.x.

15. Kadowaki T, Kondo K. Efficacy, safety and dose-response relationship of teneligliptin, a dipeptidyl peptidase- 4 inhibitor, in Japanese patients with type 2 diabetes mellitus. Diabetes Obes Metab. 2013;15(9):810-8. https://doi.org/10.1111/dom. 12092.

16. Kadowaki T, Inagaki N, Kondo K, et al. Efficacy and safety of teneligliptin added to canagliflozin monotherapy in Japanese patients with type 2 
diabetes mellitus: a multicentre, randomized, double-blind, placebo-controlled, parallel-group comparative study. Diabetes Obes Metab. 2018;20(2): 453-7. https://doi.org/10.1111/dom.13079.

17. Kadowaki T, Kondo K. Efficacy and safety of teneligliptin in combination with pioglitazone in Japanese patients with type 2 diabetes mellitus. J Diabetes Investig. 2013;4(6):576-84. https://doi. org/10.1111/jdi.12092.

18. Kadowaki T, Kondo K. Efficacy and safety of teneligliptin added to glimepiride in Japanese patients with type 2 diabetes mellitus: a randomized, double-blind, placebo-controlled study with an openlabel, long-term extension. Diabetes Obes Metab. 2014;16(5):418-25. https://doi.org/10.1111/dom. 12235 .

19. Kadowaki T, Kondo K, Sasaki N, et al. Efficacy and safety of teneligliptin add-on to insulin monotherapy in Japanese patients with type 2 diabetes mellitus: a 16-week, randomized, double-blind, placebo-controlled trial with an open-label period. Expert Opin Pharmacother. 2017;18(13):1291-300. https://doi.org/10.1080/14656566.2017.1359259.

20. Kim MK, Rhee EJ, Han KA, et al. Efficacy and safety of teneligliptin, a dipeptidyl peptidase- 4 inhibitor, combined with metformin in Korean patients with type 2 diabetes mellitus: a 16-week, randomized, double-blind, placebo-controlled phase III trial. Diabetes Obes Metab. 2015;17(3):309-12. https:// doi.org/10.1111/dom.12424.

21. Kim Y, Kang ES, Jang HC, et al. Teneligliptin versus sitagliptin in Korean patients with type 2 diabetes inadequately controlled with metformin and glimepiride: a randomized, double-blind, non-inferiority trial. Diabetes Obes Metab. 2019;21(3):631-9. https://doi.org/10.1111/dom.13566.

22. Kadowaki T, Marubayashi F, Yokota S, Katoh M, Iijima H. Safety and efficacy of teneligliptin in Japanese patients with type 2 diabetes mellitus: a pooled analysis of two phase III clinical studies. Expert Opin Pharmacother. 2015;16(7):971-81. https://doi.org/10.1517/14656566.2015.1032249.

23. TENELIA $^{\circledR} 20 \mathrm{mg}, 40 \mathrm{mg}$ tablets. interview form, 13th version. 2018 (in Japanese). https://medical. mt-pharma.co.jp/di/file/if/tnl.pdf. Accessed 17 Sept 2019.

24. Kadowaki T, Haneda M, Ito $H$, et al. Safety and efficacy of long-term treatment with teneligliptin: interim analysis of a post-marketing surveillance of more than 10,000 Japanese patients with type 2 diabetes mellitus. Expert Opin Pharmacother. 2018;19(2):83-91. 14656566.2017.1420165.
25. Haneda M, Kadowaki $\mathrm{T}$, Ito $\mathrm{H}$, et al. Safety and efficacy of teneligliptin in patients with type 2 diabetes mellitus and impaired renal function: interim report from post-marketing surveillance. Diabetes Ther. 2018;9(3):1083-97. https://doi.org/ 10.1007/s13300-018-0416-2.

26. Kadowaki $\mathrm{T}$, Haneda $\mathrm{T}$, Ito $\mathrm{H}$, et al. Relationship of eating patterns and metabolic parameters, and teneligliptin treatment: interim results from postmarketing surveillance in Japanese type 2 diabetes patients. Adv Ther. 2018;35(6):817-31. https://doi. org/10.1007/s12325-018-0704-2.

27. Matsuo S, Imai E, Horio M, et al. Revised equations for estimated GFR from serum creatinine in Japan. Am J Kidney Dis. 2009;53(6):982-92. https://doi. org/10.1053/j.ajkd.2008.12.034.

28. KDIGO Clinical Guideline Working Group. Chapter 1: definition and classification of CKD. Kidney Int Suppl. 2013;3(1):19-62. https://doi.org/10. 1038/kisup.2012.64.

29. Yabe D, Seino Y. Dipeptidyl peptidase-4 inhibitors and sulfonylureas for type 2 diabetes: friend or foe? J Diabetes Investig. 2014;5(5):475-7. https://doi. org/10.1111/jdi.12229.

30. Unno Y, Ikeda R, Ochiai K, Hayashi N. Safety and efficacy of long-term combination therapy with linagliptin (Trazenta ${ }^{\circledR}$ tablet $5 \mathrm{mg}$ ), a DPP-4 inhibitor, in patients with type 2 diabetes mellitus-interim report from a special drug use-results survey. J New Rem Clin. 2018;67(7):799-822 (in Japanese).

31. Unno Y, Ochiai K, Ikeda R, Hayashi H. Long-term safety and efficacy of linagliptin (Trazenta ${ }^{\circledR}$ tablets $5 \mathrm{mg}$ ), a DPP-4 inhibitor, in patients with type 2 diabetes mellitus-Interim report from special surveillance in patients who started linagliptin treatment as monotherapy. J New Rem Clin. 2018;67(6):667-88 (in Japanese).

32. Fukuda M, Doi K, Sugawara M, Mochizuki K. Efficacy and safety of sitagliptin in elderly patients with type 2 diabetes mellitus: a focus on hypoglycemia. J Diabetes Investig. 2019;10(2):383-91. https://doi.org/10.1111/jdi.12915.

33. Ohmura H, Mita T, Matsuoka J, et al. Real-world data on the incidence of macrovascular complications in Japanese patients with type 2 diabetes: the Sitagliptin Registration Type 2 Diabetes-Juntendo Collaborating Project. Diabetes Ther. 2019;10(3): 1099-111. https://doi.org/10.1007/s13300-0190626-2.

34. Umezawa S, Kubota A, Maeda H, et al. Two-year assessment of the efficacy and safety of sitagliptin in elderly patients with type 2 diabetes: post hoc analysis of the ASSET-K study. BMC Endocr Disord. 
2015;15:34. https://doi.org/10.1186/s12902-0150033-2.

35. Murayama H, Toda M, Tsumiyama I, et al. Relationship of patient background with macro- and microvascular complications: a 2-year post-marketing surveillance of vildagliptin in nearly 20,000 Japanese diabetic patients. Expert Opin Pharmacother. 2019;20(8):1037-47. https://doi.org/10. $1080 / 14656566.2019 .1585802$.

36. Umeki Y, Saito C, Nakamura Y, et al. Safety and efficacy of treatment with omarigliptin (MARIZEV ${ }^{\circledR}$ Tablets) by renal function classification-Interim analysis of a post-marketing surveillance study. J New Rem Clin. 2018;67(9):1044-74 (in Japanese).

37. Kasahara T, Tabuchi O, Kashiwagi N, Ichikawa K. Safety and efficacy of long-term therapy with dipeptidyl peptidase-4 (DPP-4) inhibitor, anagliptin $\left(\right.$ Suiny $\left.{ }^{\circledR}\right)$ in patients with type 2 diabetes mellitus 2-year interim report I of Suiny post-marketing prospective study with type 2 diabetes mellitus in Japan (SWIM-JPN). Jpn Pharmacol Ther. 2018;46(8):1293-314 (in Japanese).

38. Tabuchi O, Kasahara T, Kashiwagi N, Ichikawa K. Effect of dipeptidyl peptidase-4 (DPP-4) inhibitor, anagliptin (Suiny ${ }^{\circledR}$ ) on blood glucose and serum lipid in patients with type 2 diabetes mellitus - 2year interim report II of Suiny post-marketing prospective study with type 2 diabetes mellitus in Japan (SWIM-JPN). Jpn Pharmacol Ther. 2018;46(8):1315-29 (in Japanese).

39. Guliani A, Bishnoi A, Aggarwal D, Parsad D. Teneligliptin-associated bullous pemphigoid in an elderly man with diabetes. Postgrad Med J. 2018;94(1117):662-3. https://doi.org/10.1136/ postgradmedj-2018-136044.

40. Kage Y, Yamaguchi Y, Uchida T, et al. Case of bullous pemphigoid associated with teneligliptin accompanied by severe mucous membrane involvement. J Dermatol. 2018;45(7):e205-6. https://doi.org/10.1111/1346-8138.14237.

41. Maki N, Nishie W, Takazawa M, et al. Dipeptidyl peptidase-4 inhibitor-associated bullous pemphigoid in a patient with acquired reactive perforating collagenosis. J Dermatol. 2018;45(5):e205-6. https://doi.org/10.1111/1346-8138.14254.

42. Tanaka H, Ishii T. Analysis of patients with druginduced pemphigoid using the Japanese Adverse Drug Event Report database. J Dermatol. 2019;46(3):240-4. https://doi.org/10.1111/13468138.14741.

43. Kawaguchi Y, Shimauchi R, Nishibori N, et al. Dipeptidyl peptidase-4 inhibitors-associated bullous pemphigoid: a retrospective study of 168 pemphigoid and 9,304 diabetes mellitus patients. J Diabetes Investig. 2019;10(2):392-8. https://doi. org/10.1111/jdi.12877.

44. Schmidt E, Zillikens D. Pemphigoid diseases. Lancet. 2013;381(9863):320-32. https://doi.org/10. 1016/s0140-6736(12)61140-4.

45. Ujiie H, Muramatsu K, Mushiroda T, et al. HLADQB1*03:01 as a biomarker for genetic susceptibility to bullous pemphigoid induced by DPP-4 inhibitors. J Invest Dermatol. 2018;138(5):1201-4. https://doi.org/10.1016/j.jid.2017.11.023.

46. Ueki K, Sasako T, Okazaki Y, et al. Effect of an intensified multifactorial intervention on cardiovascular outcomes and mortality in type 2 diabetes (J-DOIT3): an open-label, randomised controlled trial. Lancet Diabetes Endocrinol. 2017;5(12): 951-64. $\quad$ https://doi.org/10.1016/s22138587(17)30327-3.

47. Sone $\mathrm{H}$, Tanaka $\mathrm{S}$, Tanaka $\mathrm{S}$, et al. Serum level of triglycerides is a potent risk factor comparable to LDL cholesterol for coronary heart disease in Japanese patients with type 2 diabetes: subanalysis of the Japan Diabetes Complications Study (JDCS). J Clin Endocrinol Metab. 2011;96(11):3448-56. https://doi.org/10.1210/jc.2011-0622.

48. Kasuga M, Ueki K, Tajima N, et al. Report of the JDS/JCA Joint Committee on Diabetes and Cancer. Diabetol Int. 2013;4(2):81-96. https://doi.org/10. 1007/s13340-013-0121-3.

49. Cancer Information Service, National Cancer Center, Japan Cancer Registry and Statistics. https:// ganjoho.jp/data/reg_stat/statistics/dl/cancer_incide nce47pref(2014-2015).xls (in Japanese). Accessed 22 Aug 2019.

50. Ministry of Health, Labour and Welfare (2016) Health and Nutrition Survey in Japan 2014. https:// www.mhlw.go.jp/bunya/kenkou/eiyou/dl/h26-hou koku-05.pdf (in Japanese). Accessed 22 Aug 2019.

51. Offurum A, Wagner LA, Gooden T. Adverse safety events in patients with chronic kidney disease (CKD). Expert Opin Drug Saf. 2016;15(12): 1597-607. https://doi.org/10.1080/14740338.2016. 1236909.

52. Alsahli M, Gerich JE. Hypoglycemia in patients with diabetes and renal disease. J Clin Med. 2015;4(5): 948-64. https://doi.org/10.3390/jcm4050948.

53. Gianchandani RY, Neupane S, Iyengar JJ, Heung M. Pathophysiology and management of hypoglycemia in end-stage renal disease patients: a review. Endocr Pract. 2017;23(3):353-62. https:// doi.org/10.4158/ep161471.Ra. 
54. Gupta S, Sen U. More than just an enzyme: dipeptidyl peptidase-4 (DPP-4) and its association with diabetic kidney remodelling. Pharmacol Res. 2019;147:104391. https://doi.org/10.1016/j.phrs. 2019.104391 .

55. Thomas MC, Paldanius PM, Ayyagari R, Ong SH, Groop PH. Systematic literature review of DPP-4 inhibitors in patients with type 2 diabetes mellitus and renal impairment. Diabetes Ther. 2016;7(3): 439-54. https://doi.org/10.1007/s13300-016-0189-4.

56. Otsuki H, Kosaka T, Nakamura K, Shimomura F, Kuwahara Y, Tsukamoto T. Safety and efficacy of teneligliptin: a novel DPP-4 inhibitor for hemodialysis patients with type 2 diabetes. Int Urol
Nephrol. 2014;46(2):427-32. https://doi.org/10. $1007 / \mathrm{s} 11255-013-0552-6$.

57. Wada N, Mori K, Nakagawa C, et al. Improved glycemic control with teneligliptin in patients with type 2 diabetes mellitus on hemodialysis: evaluation by continuous glucose monitoring. J Diabetes Complications. 2015;29(8):1310-3. https://doi.org/ 10.1016/j.jdiacomp.2015.07.002.

58. Kadowaki T, Sasaki K, Ishii M, Matsukawa M, Ushirogawa Y. Efficacy and safety of teneligliptin $40 \mathrm{mg}$ in type 2 diabetes: a pooled analysis of two phase III clinical studies. Diabetes Ther. 2018;9(2):623-36. https://doi.org/10.1007/s13300-018-0372-x. 